\title{
In situ study of model organic friction modifiers using liquid cell AFM: self-assembly of octadecylamine
}

\author{
Campen, S. ${ }^{a}$, Green, J. H. ${ }^{\text {, }}$ Lamb, G. D. ${ }^{\text {b }}$, Spikes, H.A. ${ }^{a}$ \\ a Tribology Group, Department of Mechanical Engineering, Imperial College London, SW7 2AZ, UK \\ b Castrol Ltd., Pangbourne, Reading, RG8 7QR, UK
}

\section{ABSTRACT}

Liquid cell AFM has been applied to study in situ the formation and properties of selfassembled films formed on mica surfaces by octadecylamine from alkane solution.

Mica surfaces immersed in hexadecane or dodecane at room temperature show no identifiable surface films. However when octadecylamine solution is injected into the cell a boundary film forms almost immediately. This film takes the form of irregular islands of mean diameter approximately 1 to $3 \mu \mathrm{m}$ and thickness typically $1.5 \mathrm{~nm}$ when measured in contact mode. These islands are believed to correspond to patches of vertically-oriented but tilted octadecylamine or ammonium salt held together primarily by van der Waals forces between adjacent alkyl chains. These films are quite labile in that during scanning of the tip in both tapping and in contact mode changes to the shape of the islands takes place, including consolidation of the island density in the scanned region and depletion from around this area.

In situ experiments in which the temperature of the cell is varied over time show that the initially-formed islands disappear at a temperature of ca. $35^{\circ} \mathrm{C}$ but are reformed when the cell is re-cooled. Similar tests on samples that remain immersed in solution for extended periods show more stable films, with islands being lost only above about $50-60^{\circ} \mathrm{C}$.

The work shows that liquid cell AFM has great promise for studying the formation and properties of the boundary films formed by organic friction modifiers.

\section{KEYWORDS}

Organic friction modifier; AFM; boundary friction; in situ; amine

\section{$1 \quad$ INTRODUCTION}

Organic friction modifiers (OFMs) are amphiphilic molecules that interact with tribological surfaces to reduce friction in the boundary lubrication regime. They are widely used as additives in low friction lubricant formulations, including modern, fuel-efficient engine oils. Typical OFM structures are shown in [1]. Although OFMs have been in use for almost a 
century [2], there is still considerable debate about the nature of the boundary films that they form. Much research has shown that vertically-oriented monolayers of OFMs deposited on surfaces by Langmuir-Blodgett techniques can produce low friction and this is believed to originate from the low shear strength of the interfacial region between the ends of opposing monolayers on the rubbing surfaces [3-5]. Some research has also shown that saturated chain OFMs can self-assemble from solution in oil onto solid surfaces to form full or partial, nearly vertically-oriented monolayers and that this results in low friction [6-9]. However there is also research to suggest that some films formed on and between surfaces by OFMs can be much thicker than a single pair of monolayers [10][11].

One of the main reasons for uncertainty about the nature of OFM films is that, in many cases they are relatively weakly bound to the surfaces that they lubricate. This means that when pairs of rubbed surfaces lubricated by OFMs are removed from the oil, separated and studied ex-situ to determine the nature of OFM films, we cannot be sure that the residual films analysed are representative of the films actually present within the contact. There has been considerable study of the extent to which OFMs form physically-adsorbed as opposed to chemically-adsorbed, and thus irreversible films on rubbed substrates, with variable findings depending on the nature of the OFM functional groups and on the substrate [12][13]. However even when a largely irreversibly-bound monolayer is observed ex-situ this does not preclude the possibility of an additional, thicker and more weakly bound film also being present within the contact itself.

Clearly, to understand the nature of OFM films we need experimental techniques that are able to observe and study very thin, OFM boundary films in situ, within rubbing contacts. Several such techniques do exist. Ultrathin film interferometry has shown that some OFMs can form quite thick films in water-contaminated or elevated temperature conditions [14][15]. Unfortunately this method operates in quite gentle contact conditions, with negligible solidsolid contact so as to preclude damage to the optical coatings on the transparent surface. It is not clear whether the thick films observed would persist in more severe and realistic asperity-asperity contact conditions. Various types of vibrational spectroscopy have also been used to study OFMs films in situ. The main problem here is that OFM films are generally extremely thin and so provide very weak spectra, especially using linear spectroscopic methods. Consequently, grazing angle methods such as multiple reflection or evanescent wave spectroscopies have to be employed, e.g. [16][17], which in turn means that only quite large surface areas can be probed and spatial resolution is poor. Nonlinear optics such as sum frequency spectroscopy are more suited to study very thin films, as well as being interface specific, and have been used, for example, to study changes to Langmuir Blodgett-deposited films in situ [18]. However these also suffer from limited spatial resolution.

One group of experimental tools that has been quite widely used in recent years in tribology are the scanning probe microscopies, in particular atomic force microscopy (AFM) and lateral force microscopy (LFM). AFM and LFM are able provide, respectively, maps of the topography and friction of surfaces and have proved to be particularly suited to study 
tribological surfaces including boundary lubricating films [19]. For example they have been used to measure the morphology of antiwear films [20] and to show the presence and properties of organomolybdenum films [21]. In almost all studies these techniques have been used to probe ex-situ surfaces and have rarely, if ever, been used to study actual or model OFMs on immersed surfaces. This is surprising since AFM and LFM work just as effectively (and, for LFM in some cases it has been suggested better [19]), when the substrate under study is immersed in liquid than when it is dry.

The aim of this work is to explore the use of liquid cell AFM to detect and examine, in situ, self-assembled films formed by OFM-type amphiphilic molecules on solid surfaces from solution in normal alkane. This paper first briefly outlines previous research on the application of scanning probe microscopies to study self-assembled films. It then describes new work to apply liquid cell AFM/LFM to study boundary film formation by the model OFM octadecylamine on mica. In a companion paper, liquid cell AFM/LFM is applied to study the behaviour of long chain acids on mica [22].

\section{BACKGROUND - AMPHIPHILE ADSORPTION AND IN SITU AFM}

There are two main methods of preparing amphiphilic films on solid surfaces. One is the Langmuir-Blodgett (LB) approach, where the film is initially formed at a liquid-air interface and then transferred to a solid surface as the latter is drawn through the film. The main advantage of this technique is that it is not limited to naturally-occurring adsorption processes that take place at the solid-liquid interface and can thus provide well-defined monolayer structures on solid surfaces. For example the density of the film can be controlled prior to transference, multilayers can be generated, and films of surfactant that do not normally occur by adsorption from the liquid phase can be prepared and studied. The preparation and study of LB films forms a large and significant body of the literature on OFMs, with the assumption often being made that, when similar frictional behaviour is seen with OFM solutions as with LB monolayers, the similarity arises because OFMs also form close-packed monolayers.

The other main approach is so-called "self-assembly", when the amphiphiles of interest are allowed to adsorb, and possibly then rearrange or react, on the substrate from the vapour or more commonly from liquid phase, to form full or partial "self-assembled monolayers" or SAMs. Of these, the most realistic method of formation from the point of view of OFM behaviour is clearly adsorption on surfaces during immersion in solution in liquid phase. Until the late 1990s, AFM and LFM were applied primarily ex situ to surfaces that had been withdrawn from the liquid phase, sometimes termed "quenched" films. Excess solution was removed by solvent evaporation, draining, rinsing or blowing dry $\mathrm{N}_{2}$ gas across the surface. This ex situ approach has a number of potential problems including the following.

- Molecular re-arrangement and increased coverage due to precipitation onto surface may occur as solvent evaporates. 
- Langmuir-Blodgett-type films may deposit onto immersed substrates during introduction to or removal from surfactant solution.

- Weakly adsorbed species, especially multilayers, that are only be stable when immersed, may be damaged during removal from the solution phase.

- Contamination of a SAM may take place during transfer in air between preparation and imaging.

To address these problems, AFM liquid cells were developed in the 1990s to enable AFM and LFM to be carried out on substrates that remain fully immersed in test solution, i.e. "in situ". Since then, AFM liquid cells have become quite widely employed, initially for studying SAMs and, more recently for research on the adsorption behaviour of biological materials such as proteins [23].

The use of an AFM liquid cell to study SAM formation appears to have been first reported by Woodward and Schwartz in 1996 [24], although scanning tunnelling microscopy (STM) at the liquid-solid interface was applied before this [25]. Three studies in 1998 considerably advanced the approach. $\mathrm{Li}$ et al. investigated the self-assembly of octadecyltrimethylammonium bromide from aqueous solution onto mica and showed the initial formation of monolayer islands that coalesced to eventually form complete surface coverage [26]. Xu and co-workers monitored the formation of alkanethiols from butanol solution on to gold surface and noted the initial formation of horizontally-oriented molecules, followed by rearrangement to form $2 \mathrm{~nm}$ high islands that eventually formed a continuous monolayer [27]. Doudevski et al. studied SAM formation of octadecylphosphonic acid from tetrahydrofuran (THF) on mica [28]. Again SAM growth began with the initiation of submonolayer islands that grew and eventually coalesced, although a full monolayer was not reached. In 1999 Resch et al. studied the self-assembly of octadecylsiloxane molecules from toluene onto mica using both in situ and ex situ AFM methods and concluded that the in situ approach was more suited to study SAM formation [29]. A similar study was carried out on silicon surfaces by Leitner and co workers [30]. Using the in situ method they found that fractally-shaped islands formed rapidly and then grew during a slower process by in-filling the gaps. The kinetics of SAM film development was reviewed in 2001 by Schwartz [31].

Although considerable research using AFM, both ex situ and in situ, has been carried out on SAM film formation on solid surfaces, most of this has focussed on just a handful of surfactant types. The two most widely studied have been the alkyl silanes (or siloxanes) [32] and the n-alkane thiols [33][34]. Upon hydrolysis the former are able to form very strongly bound monolayers on many surfaces due to covalent bonding both between the molecules and the substrate and also between the headgroups of the amphiphiles themselves. This means that they are widely used in coating technology to produce tailor-made hydrophilic and hydrophobic surfaces. The n-alkane thiols are able to form quite strong, close-packed monolayers on noble metals such as gold and have been widely used in nanotechnology to study the intrinsic properties of monolayer films. Unfortunately neither of these species, 
although of interest in nanotribology in general, is representative of OFMs as used in liquid lubricants. A third species that is commonly used in SAM studies are the quaternary alkyl ammonium salts (QATS). These are widely used as cationic surfactants, fabric conditioners and antistatic agents, but again have little direct relevance to OFMs since they are waterrather than oil-soluble and tend to form bilayers from polar solvents on polar surfaces rather than the monolayers normally formed from non-polar solvents. Mellot and Schwartz combined ex situ and in situ AFM to study the film formation of octadecyltrimethylammonium bromide on mica [35]. They showed that below $\sim 50^{\circ} \mathrm{C}$, bilayer-thick islands formed but at higher temperature these islands disappeared to leave a homogeneous $2 \mathrm{~nm}$ thick layer.

Apart from the above, Schwartz et al. has used in situ AFM to study alkylphosphonic acid on mica [36-38] but work on most other amphiphiles has employed ex situ studies, and includes study of films formed by fatty acids [39-42], fatty alcohols [43-45] and fatty amines [46][47]. The application of AFM to study SAMs for nano-lubrication has been reviewed by Cheng and $\mathrm{Hu}$ [48].

It is quite surprising that in situ AFM using a liquid cell has not been widely used to study the self-assembly of OFMs on surfaces since, as this study will show, it has the potential to reveal valuable insights into OFM film formation and behaviour. This paper describes the application of liquid cell AFM to investigate the nature and properties of the boundary films formed by the model OFM octadecylamine.

\section{EXPERIMENTAL METHODS AND MATERIALS}

All measurements were made using a Veeco Multimode SPM with Nanoscope IV controller and either a vertical "J" or "E" scanner. The liquid cell was glass, with inlet and outlet holes to allow flow of liquid to and from the cell. The test set-up is shown in Fig. 1. A gold wire was used to hold the cantilever in place. The liquid cell was fully removable from the AFM head so that it could be cleaned at the end of each experiment. Liquids were introduced into the liquid cell via pipette. In some cases the surface was first imaged in hydrocarbon base oil and then additive-containing solution was injected and the surface imaged further. In other cases, when it was desired that the concentration of additive be known accurately, the surface was imaged only in the additive solution. Since there was no flow of base oil out of the liquid cell, it should be noted that in cases where the surface was first imaged in base oil, the actual concentration of additive was less than that of the additive-containing solution due to dilution inside the liquid cell. It is estimated that the volumes of base oil and additive solution injected were approximately $0.03 \mathrm{ml}$ and $0.02 \mathrm{ml}$ respectively, so for an additive solution of $0.01 \mathrm{M}$ concentration, it is estimated that the actual concentration of additive after injection would be ca. $0.004 \mathrm{M}$. 

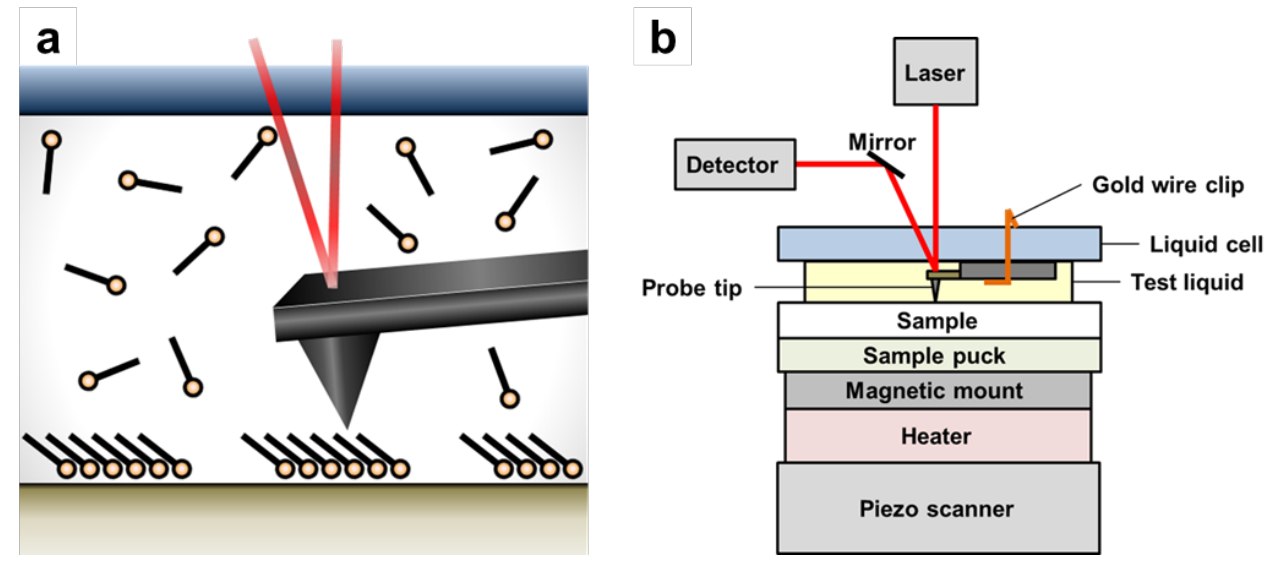

Fig. 1 Schematic of AFM operation in liquid (a) and labelled diagram of AFM apparatus (b)

Both contact and tapping modes were used. In contact mode, height and lateral force images were obtained, while in tapping mode, height and phase images were recorded. Triangular $\mathrm{Si}_{3} \mathrm{~N}_{4}$ cantilevers (model NP-S, Veeco Probes Ltd.) with a nominal spring constant of $0.12 \mathrm{Nm}^{-1}$ were used for both modes of operation. SEM micrographs of the AFM cantilever revealed that the AFM tip was rounded and had a curvature of ca. $40 \mathrm{~nm}$ radius. AFM cantilevers were calibrated using the reference cantilever method [49]. The measured spring constants were found to be in good agreement with the nominal value. In contact mode a typical cantilever deflection of $1 \mathrm{~V}$ was used which, taking into account that the deflection sensitivity on a hard surface was $57 \mathrm{nmV}^{-1}$, is equivalent to a load of $6.8 \mathrm{nN}$. In order to obtain lateral force images the fast-scan direction was set perpendicular to the long axis of the cantilever, i.e. $90^{\circ}$ scan angle. The slow-scan axis is top to bottom in AFM images. Lateral force images show the trace friction; the approximate half-width of the friction loop. TMR (trace minus retrace) friction images are not used as in some cases they displayed anomalies due to hysteresis of the open-loop scanner. For tapping mode the drive frequency in liquid (5-12 kHz) is typically much less than observed in air (200-300 KHz). Also, a higher drive amplitude (ca. $500 \mathrm{mV}$ ) was needed compared to $30 \mathrm{mV}$ in air. This is because oscillations are dampened in liquid.

To investigate the effect of temperature, a sample heater attachment (Veeco Instruments, Santa Barbara, California, USA) was placed directly beneath the magnetic specimen plate inside the AFM scanner. A rate of heating of $1^{\circ} \mathrm{Cmin}^{-1}$ was used. Upon reaching the temperature setpoint, the sample was allowed to equilibrate for $5 \mathrm{~min}$ before re-engaging the tip and commencing scanning.

The additive octadecylamine $\left(\geq 99.0 \%, 269.51 \mathrm{gmol}^{-1}\right)$ was used as supplied. Hexadecane (99\%) and dodecane (99\%), both used as base oils, were cleaned with silica (Fluka, chromatography, 60) and alumina (Sigma-Aldrich, Brockmann Activity I, basic) molecular sieves and stored over alumina to be filtered immediately before use. Solutions of 
octadecylamine in base oil were prepared at concentrations of 0.01 and $0.001 \mathrm{M}$ as required. All reagents were acquired from Sigma-Aldrich.

Muscovite mica was obtained as $14 \mathrm{~mm}$ diameter discs from Agar Scientific Ltd (Stansted, UK). The mica specimens were attached to steel discs using Araldite 2-part epoxy resin ready for mounting on the magnetic stage in the AFM head. Immediately before use, the mica was freshly cleaved in air using adhesive tape to give a clean substrate for additive adsorption.

\section{$4 \quad$ RESULTS}

\subsection{OCTADECYLAMINE ON MICA}

The adsorption of octadecylamine onto mica surfaces was studied in situ using liquid cell AFM. In a preliminary experiment, an air-cleaved mica surface was first imaged in hexadecane and then after the injection of $0.01 \mathrm{M}$ octadecylamine solution in hexadecane via pipette. The estimated resulting concentration of octadecylamine solution was ca 0.004 M.

In hexadecane, a flat, featureless surface was observed using tapping mode, while after the introduction of octadecylamine solution, islands were observed on the surface, see Fig. 2. These islands formed before the first scan, i.e. within 6 minutes, to give a surface coverage of ca. $53 \%$ that did not change over a time of 100 minutes.
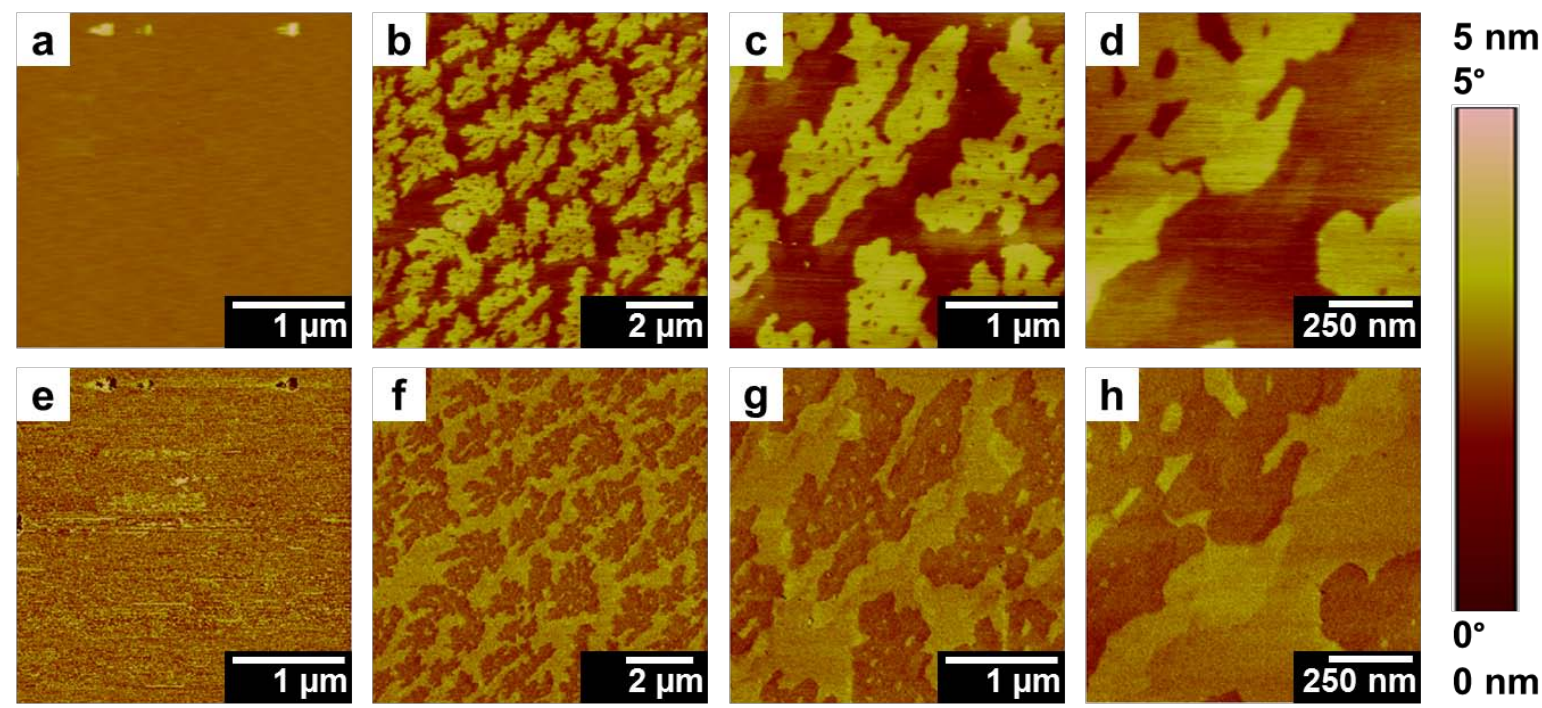

$0 \mathrm{~nm}$

Fig. 2 Tapping mode AFM height ( $a, b, c, d)$ and simultaneously obtained phase (e, f, g, h) images of mica in hexadecane (a) and after introduction of $0.01 \mathrm{M}$ octadecylamine solution in hexadecane $(b, c, d)$

The islands were irregular in shape, contained pinhole inclusions and had diameter from 1 to $3 \mu \mathrm{m}$ and a height of $1.5 \mathrm{~nm}$. This suggests a monolayer of octadecylamine where 
molecules are tilted from the surface normal by $51^{\circ}$, assuming that the length of one octadecylamine molecule is $2.4 \mathrm{~nm}$ [47].

Contact mode AFM was also applied. To measure island height in this mode, imaging was undertaken at a very low deflection set point value, near to the pull-off point. This was because height images obtained at higher deflection set points and hence higher loads were of poorer quality. Again, the island height was ca. $1.5 \mathrm{~nm}$. Imaging under these conditions led to augmentation of the surface coverage, as can be seen in Fig. 3, where images from three successive $3 \mu \mathrm{m} \times 3 \mu \mathrm{m}$ scans are shown. It can be seen that the islands grow in size and lose their rough edges, although the pinholes remain. A final height image obtained at a larger scan size of $10 \mu \mathrm{m} \times 10 \mu \mathrm{m}$ shows that a void in the film has been created around the periphery of the previously-scanned area; this also suggests that a reorganisation of the film has taken place. It is postulated that reorganisation is the dominant effect although adsorption of new molecules may also occur to some small degree. Reorganisation in this manner suggests that the octadecylamine molecules are at least partially labile, being capable of relocating via lateral movements across the mica surface.
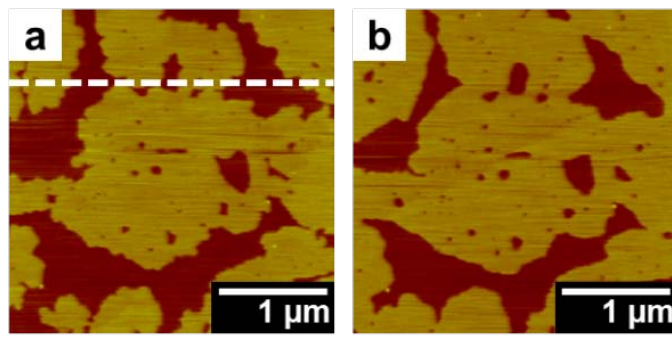

\section{$5 \mathrm{~nm}$}
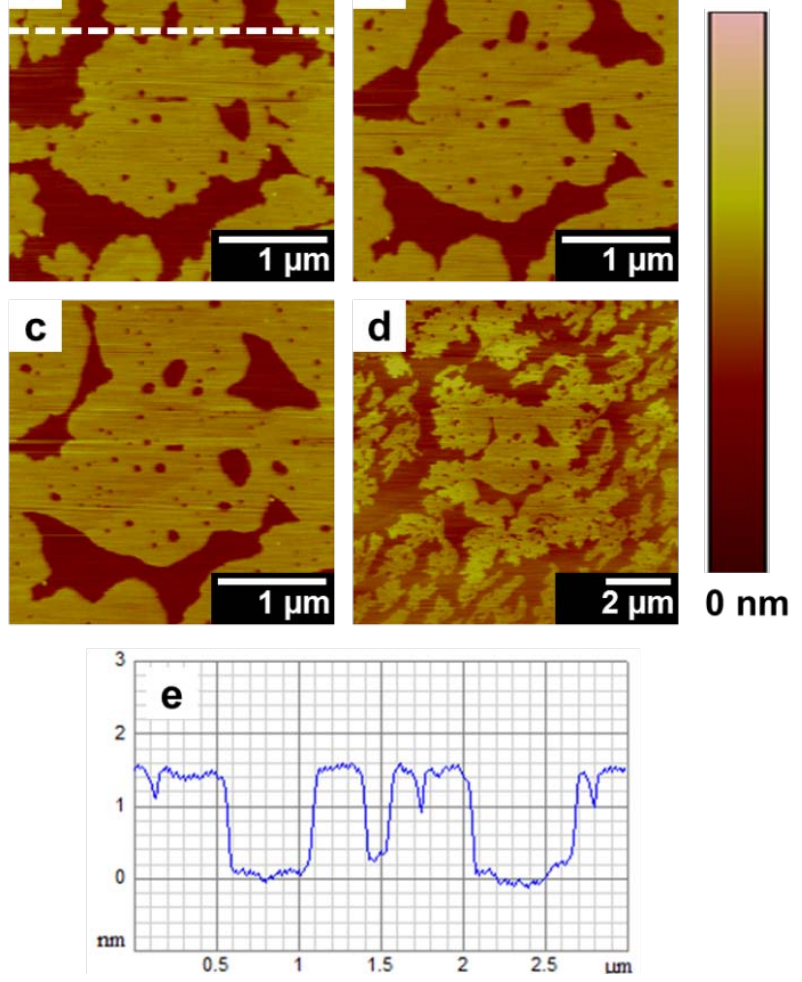

Fig. 3 Contact mode AFM height images ( $a, b, c, d)$ of mica in octadecylamine solution in hexadecane showing film growth promoted by successive scanning near the pull off point; line profile of a (e)

To obtain a friction image in contact mode, the deflection setpoint and hence the load applied by the tip was increased. It was observed that the friction of the octadecylamine islands was lower than that of the mica surface, as shown in Fig. 4. At this applied load, the 
quality of the simultaneously-obtained height image was impaired but it was clear that the height of the islands fell from 1.5 to just $0.5 \mathrm{~nm}$. This implies load-induced tilting of the octadecylamine molecules within the island film to a very high value of $78^{\circ}$ from the surface normal.
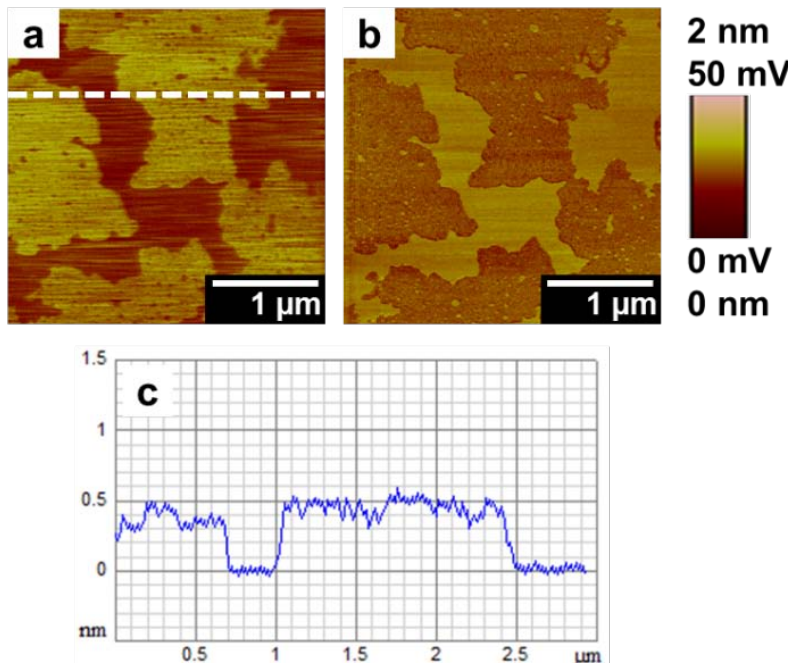

Fig. 4 Contact mode AFM height (a) and friction (b) images of mica in octadecylamine solution in hexadecane; line profile analysis of a (c); n.b. bright contrast in (b) is high friction

In a second series of experiments, an air-cleaved mica surface was imaged in a solution of octadecylamine in dodecane at a concentration of $0.001 \mathrm{M}$. In this case, the surface was not previously scanned in dodecane so the concentration used is known to be exact. In the first instance the film was scanned in tapping mode. At a scan size of $3 \mu \mathrm{m} \times 3 \mu \mathrm{m}$ it was observed that the film was manipulated by the tip with successive scanning of the same area, Fig 5.
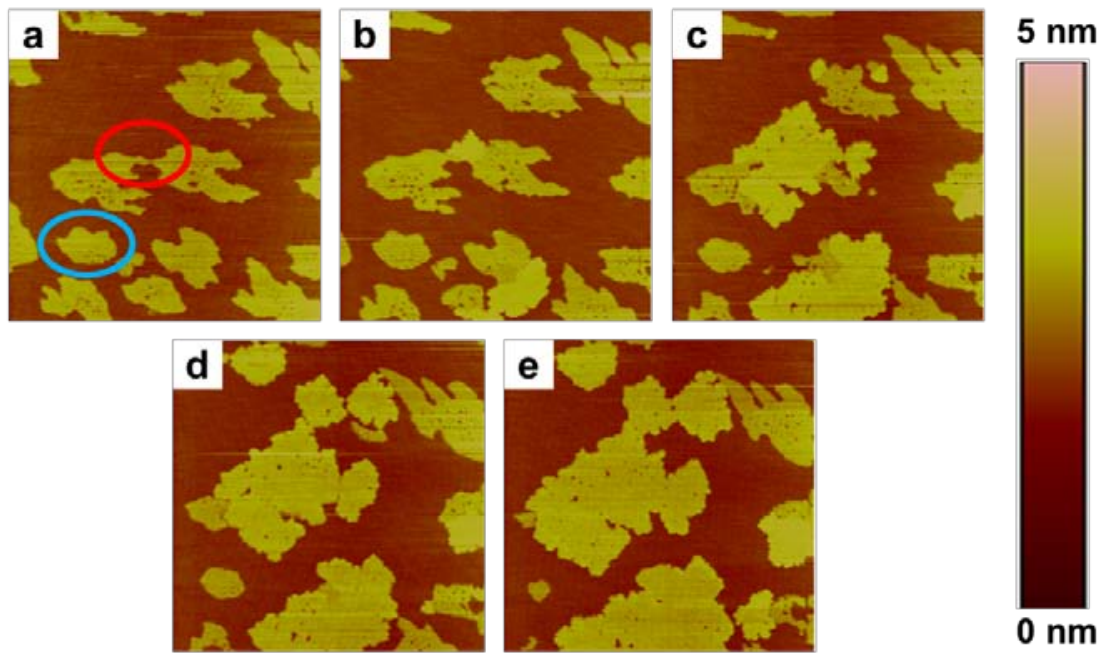

Fig. 5 Tapping mode AFM height images of mica in $0.001 \mathrm{M}$ octadecylamine solution in dodecane illustrating film manipulation with successive $3 \mu \mathrm{m}$ scans (shown in alphabetical order); red and blue rings in (a) denote areas of film growth and film depletion respectively 
This is similar to the above experiment, where the octadecylamine film was manipulated in contact mode. However, here film growth does not simply occur around the perimeter of pre-existing islands and close inspection reveals that, with successive scans, some islands are depleted while in other regions film growth occurs. Generally film growth occurs at the near juncture of two pre-existing islands. One example of an island that is depleted is circled in blue and one example of an area where film growth occurs is circled in red in Fig. 5A. It appears that manipulation of the octadecylamine film generally results in the generation of a lesser number of larger islands from a greater number of smaller islands.

A further test of film manipulation in tapping mode was made at a new location on the substrate surface and is shown in Fig. 6.
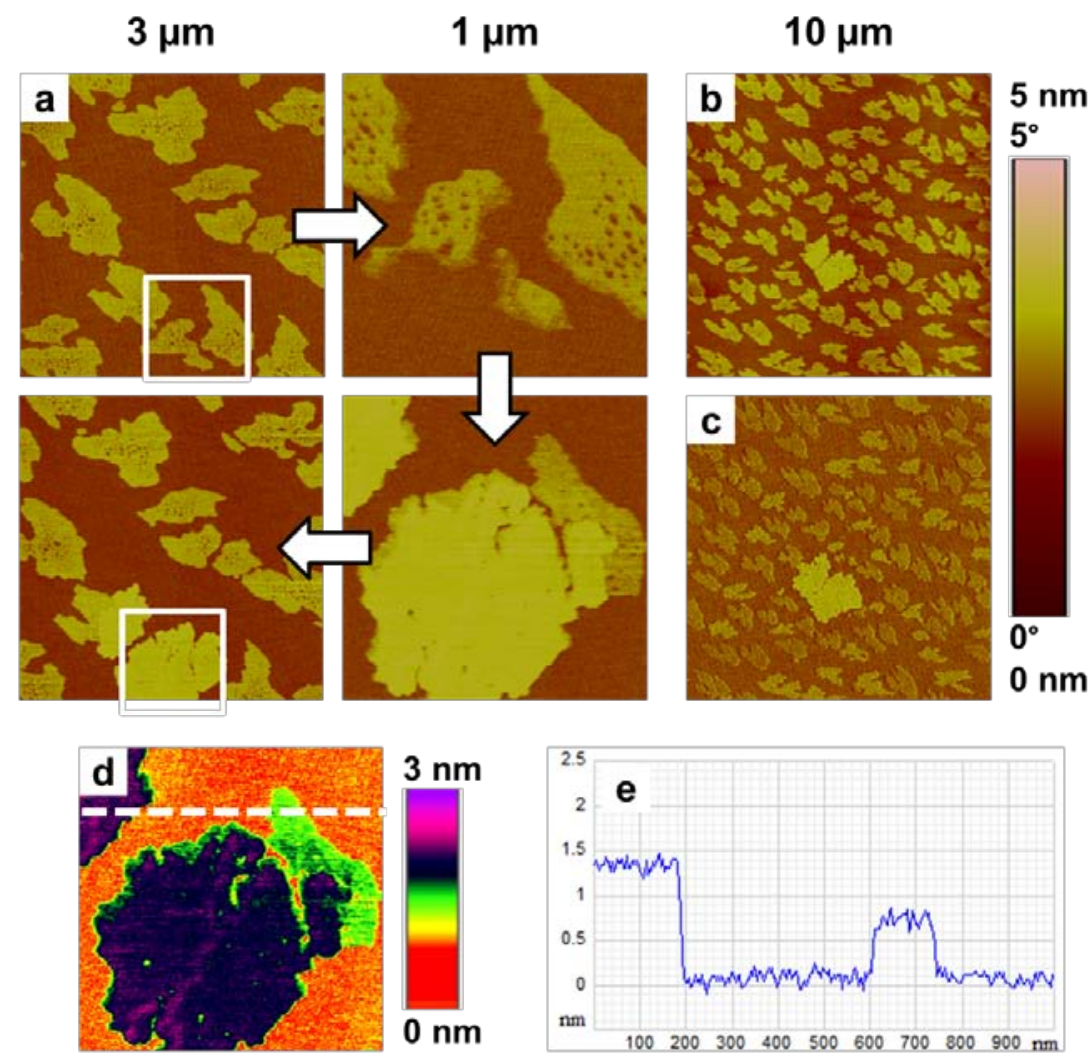

Fig. 6 Tapping mode AFM height ( $a, b, d)$ and phase (c) images of mica in $0.001 \mathrm{M}$ octadecylamine solution in dodecane illustrating scanning-induced film manipulation (a) and the resultant changes in the film (b, c); line profile of $d(e)$; the colour of image $d$ has been altered to highlight augmentation of film height

This shows that film manipulation is limited to the $1 \mu \mathrm{m} \times 1 \mu \mathrm{m}$ scanned area since, when the scan size is subsequently increased, it is observed that islands outside the previously scanned area are not affected. This proves that the observed changes in the film are not simply time-dependent, autonomous reorganisations. NB. The area immediately outside the white box shown in the fourth image of Fig. 6a also appears to display augmented film height; this is due to $X Y$ drift that occurred whilst scanning at a small scan size of $1 \mu \mathrm{m}$. Manipulation by the tip in tapping mode leads to a reduction in the number of pinhole 
inclusions as well as an augmentation of the film height from $0.9 \mathrm{~nm}$ to $1.4 \mathrm{~nm}$, indicative of a decrease in octadecylamine molecular tilt angle from the surface normal from $68^{\circ}$ to $54^{\circ}$. The phase image also suggests that the elastic properties of the manipulated island are altered.

Tapping mode AFM of two previously unscanned areas revealed two different appearances of the film, see Fig. 7.

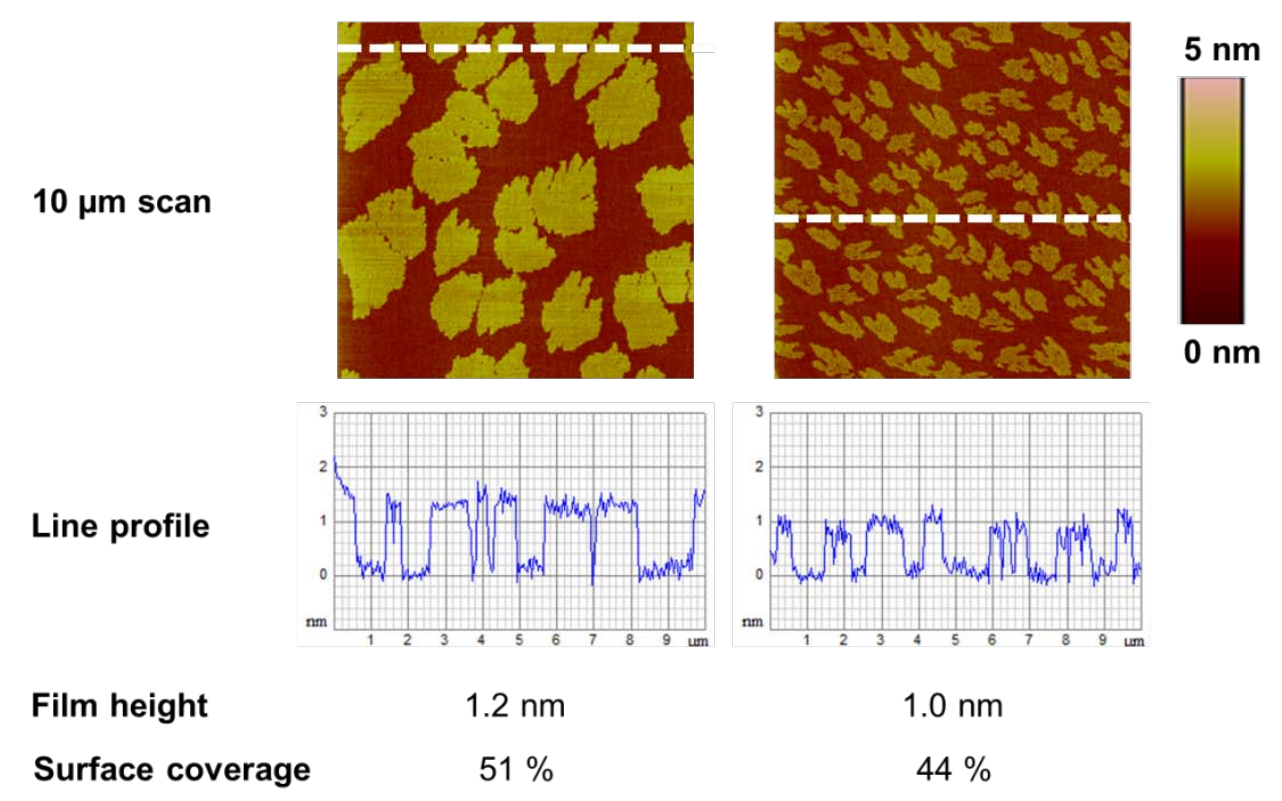

Fig. 7 Tapping mode AFM height images of mica in $0.001 \mathrm{M}$ octadecylamine solution in dodecane from two different previously unscanned areas

In one location the islands are larger in diameter and thicker, with a height of $1.2 \mathrm{~nm}\left(60^{\circ}\right.$ molecular tilt from surface normal), while at the other location the islands are smaller in diameter and thinner, with a height of $1.0 \mathrm{~nm}\left(65^{\circ}\right.$ molecular tilt from surface normal). In both instances the surface coverage of the film is similar, being $51 \%$ for the former and $44 \%$ for the latter. Fig. 8 shows contact mode height and lateral force scans of the same surface, which confirm that the octadecylamine islands have lower lateral force than their surrounding regions.

It is noted that the estimated concentration of $0.004 \mathrm{M}$ for the preliminary experiment with octadecylamine in hexadecane is a reasonable approximation, as the surface coverage of $54 \%$ achieved in the first experiment is slightly higher than that achieved with a known concentration of $0.001 \mathrm{M}$, which is on average $48 \%$. It is expected that higher surface coverages will be obtained at higher concentrations. 

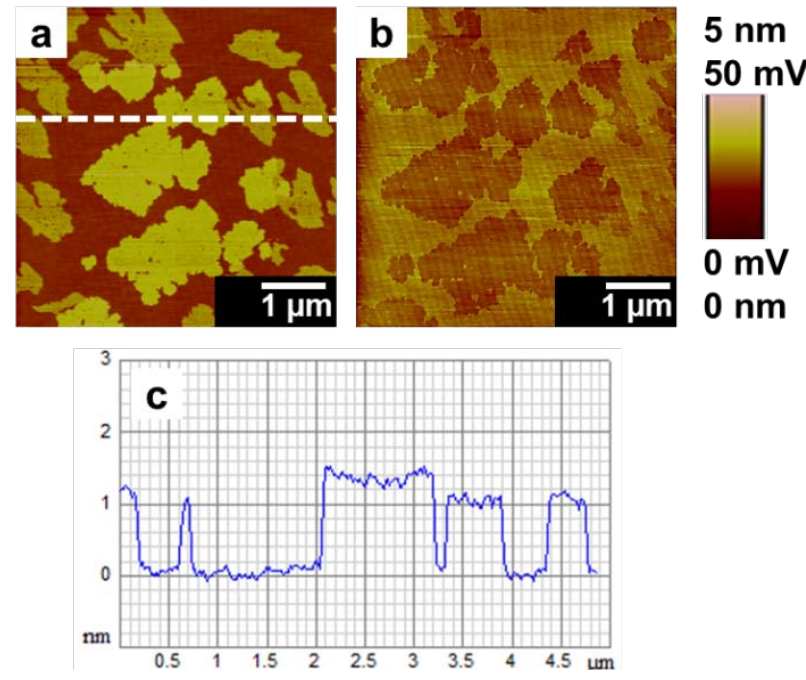

Fig. 8 Contact mode AFM height (a) and friction (b) images of mica in $0.001 \mathrm{M}$ octadecylamine solution in dodecane; line profile of a (c)

\subsection{THE EFFECT OF TEMPERATURE}

The effect of temperature on octadecylamine monolayer films self-assembled on mica was also investigated. Firstly, an air-cleaved mica substrate was imaged in hexadecane at a room temperature of $24.5^{\circ} \mathrm{C}$. Octadecylamine, at $0.01 \mathrm{M}$ solution in hexadecane, was then injected into the liquid cell mid-scan and it was observed that monolayer height film formation was instantaneous, see Fig. 9. It is noteworthy that the surface coverage is greater than that observed in the previous experiment; however, after one heating-cooling cycle the surface coverage falls to a value more in keeping with the earlier result. The initial larger coverage may result from a locally high amine concentration in solution due to slow mixing as the octadecylamine solution is injected into the hexadecane-containing cell.
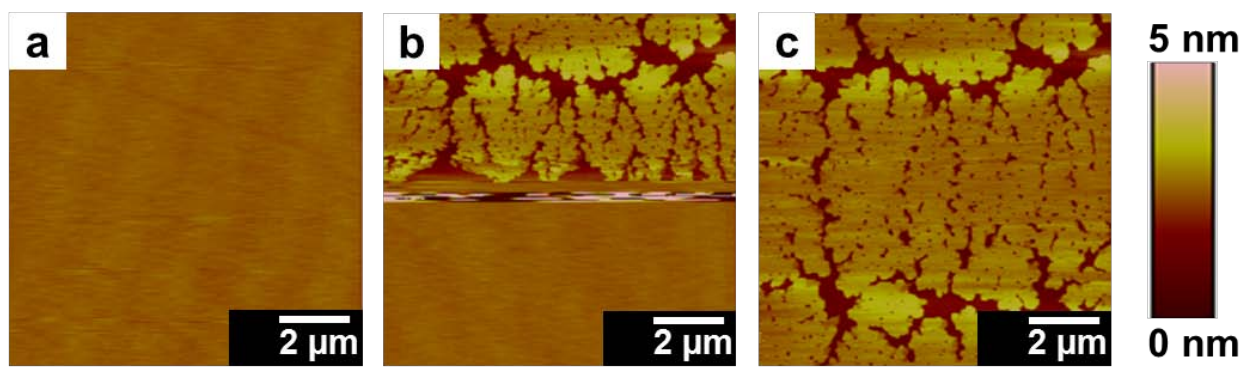

Fig. 9 Contact mode AFM height images of mica in hexadecane (a) and during (b) and after (c) injection of $0.01 \mathrm{M}$ octadecylamine solution into hexadecane, room temperature $=24.5^{\circ} \mathrm{C}$

The specimen was then heated to $30^{\circ} \mathrm{C}$, then to $35^{\circ} \mathrm{C}$ and finally to $40^{\circ} \mathrm{C}$ before cooling to $31.5^{\circ} \mathrm{C}$. The results are displayed in Fig. 10. At a temperature of $30^{\circ} \mathrm{C}$ the surface coverage of the monolayer film was reduced. Desorption chiefly occurred at pinholes inside the islands and to a lesser degree at the edge of islands. At $35^{\circ} \mathrm{C}$ all the film was removed and 
the height images obtained were slightly noisy; this may be due to very small, isolated islands of adsorbed octadecylamine molecules or the presence of a disordered film that covers the surface. Upon further heating to $40^{\circ} \mathrm{C}$ the height images remained unchanged and still exhibited noise. After cooling to $31.5^{\circ} \mathrm{C}$ it was observed that the octadecylamine monolayers had reformed on the mica surface. The film existed as discrete islands, not a near-continuous film as observed prior to heating.

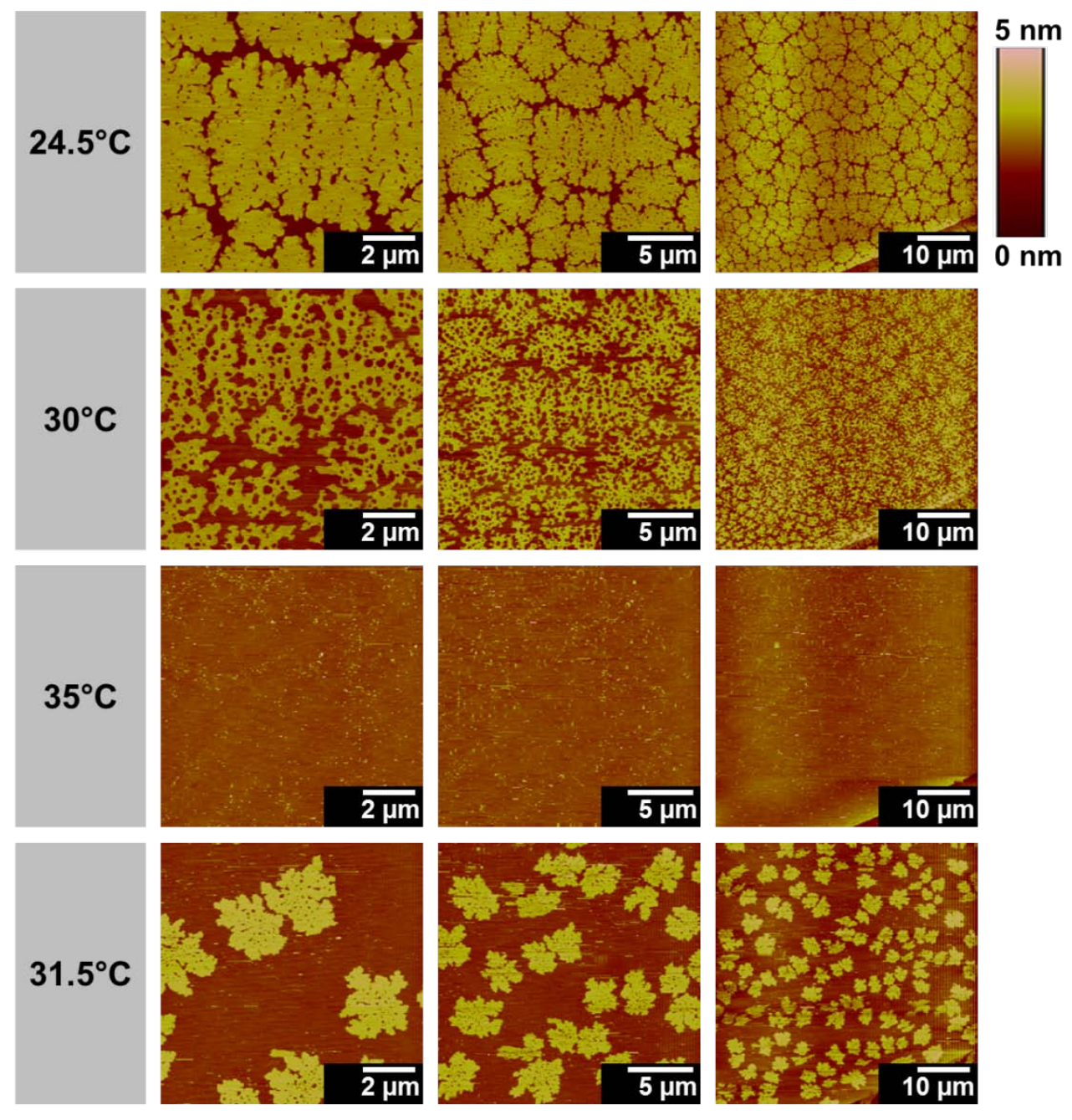

Fig. 10 The effect of temperature on octadecylamine submonolayer; contact mode AFM height images of mica in diluted $0.01 \mathrm{M}$ octadecylamine solution in hexadecane during one heating-cooling cycle

The specimen was left in situ for a period of $20 \mathrm{~h}$ and the film was imaged again. Discrete, low lateral force islands were observed on the surface, Fig. 11. The height of the film was determined to be $1.4 \mathrm{~nm}$ and the surface coverage was calculated to be $47 \%$. 

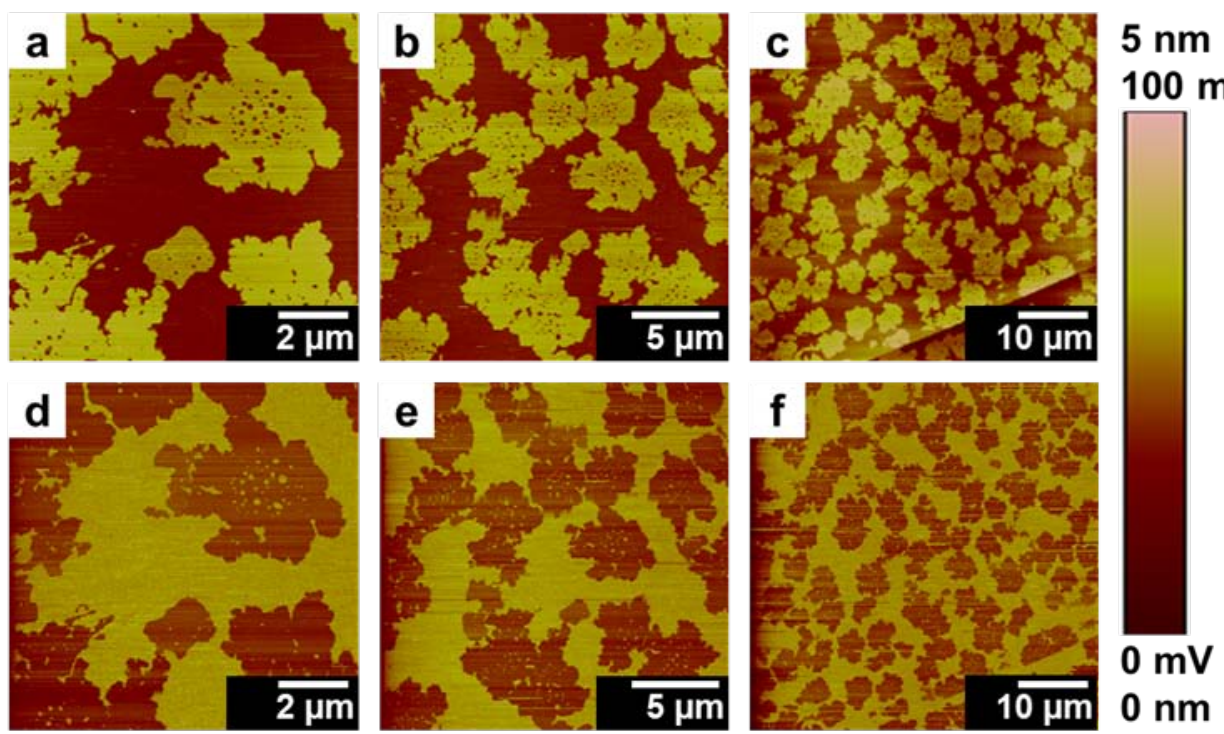

Fig. 11 Contact mode AFM height ( $a, b, c)$ and friction ( $d, e, f)$ images of mica in octadecylamine solution $20 \mathrm{~h}$ after performing one heating and cooling cycle, temperature $=$ $28^{\circ} \mathrm{C}$

The specimen was then reheated at smaller intervals of $2.5^{\circ} \mathrm{C}$ from 30 to $65^{\circ} \mathrm{C}$. Here, it was observed that desorption occurred gradually with increasing temperature up to $60^{\circ} \mathrm{C}$, see Fig. 12. Desorption was predominantly from the edges of islands, not at pinholes as previously observed. The extent of the film was significantly reduced at a temperature of $50^{\circ} \mathrm{C}$; but was not completely removed until a temperature of $65^{\circ} \mathrm{C}$. These results indicate that allowing the octadecylamine monolayer to stabilise in solution for an extended period of 20 hours before heating endows the film with greater thermal stability.

\section{$5 \quad$ DISCUSSION}

The results show clearly that octadecylamine adsorbs spontaneously on mica from solution in alkanes to form low lateral force, monolayer islands. The octadecylamine is evidently quite weakly bound to the surfaces since some rearrangement as well as growth of the islands occurs in both contact and tapping mode.

Film formation by octadecylamine on mica has been extensively studied by Benitez et al. using an ex situ AFM approach and it is of interest to compare the finding of this in situ study with their work. Benitez and co-workers immersed mica in both chloroform [45][46][50] and ethanol [51] solutions of octadecylamine before removing the samples and drying them in a stream of $\mathrm{N}_{2}$ gas. The samples were then stored for varying periods of "ripening" before study with contact mode AFM. These ex situ studies observed island-like monolayer structures after immersion in chloroform, although multilayer films were formed from ethanol solvent. Recent AFM images of films formed from chloroform, e.g. in [52] are very similar in appearance to those found in the current study. The height of the observed islands was 
initially ca. $1.65 \mathrm{~nm}$, corresponding to a tilt angle of $47^{\circ}$, but after prolonged storage in air this reduced to $1.2 \mathrm{~nm}$ and eventually to $1.0 \mathrm{~nm}$, implying much greater tilt [46]. A possible reason for this change over time is described below.

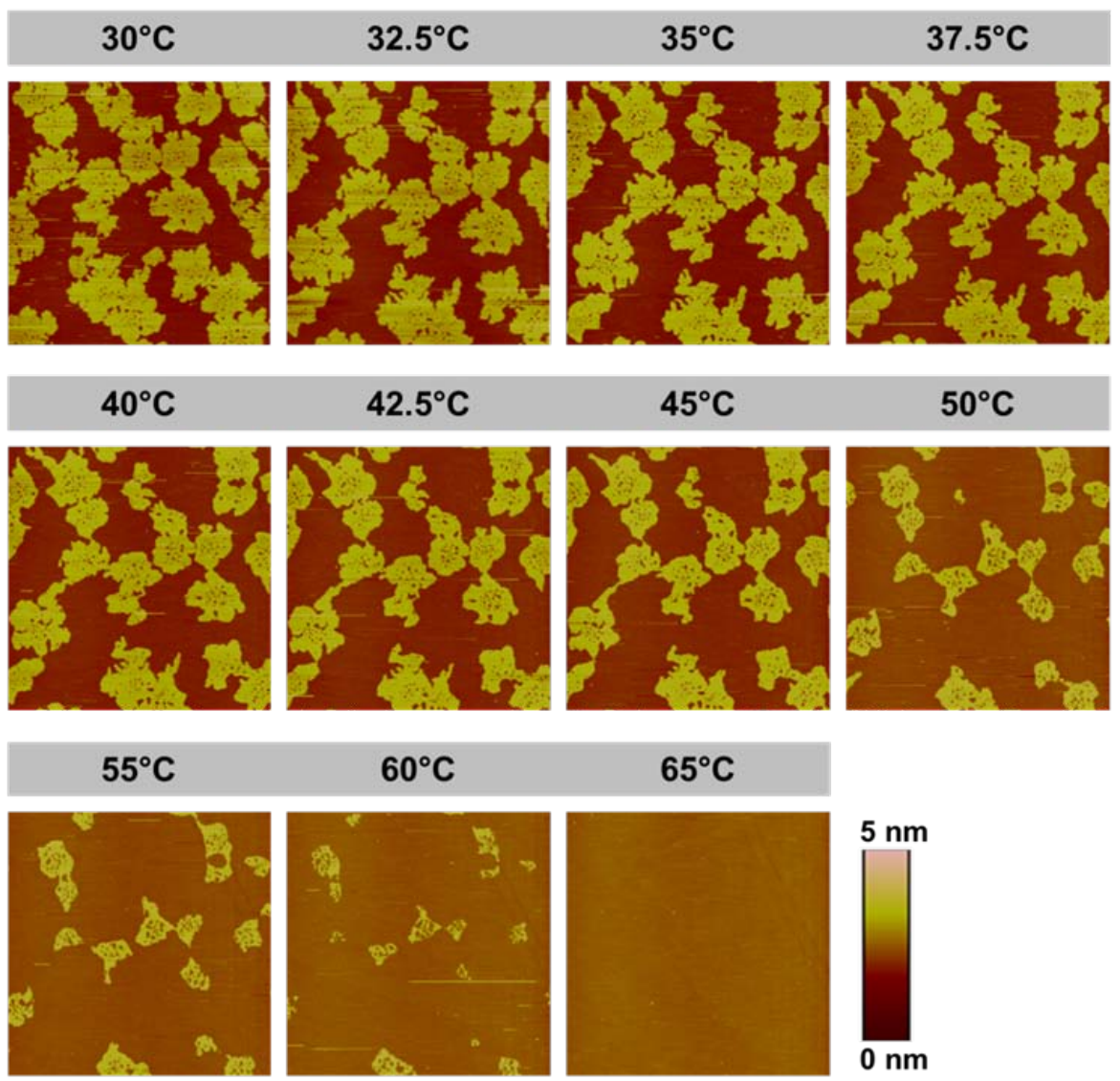

Fig. 12 The effect of temperature on octadecylamine submonolayer during a second heating cycle; contact mode AFM height images of mica in diluted $0.01 \mathrm{M}$ octadecylamine solution in hexadecane $20 \mathrm{~h}$ after the first heating-cooling cycle, scan size $=20 \mu \mathrm{m}$

Benitez et al. also found the octadecylamine islands to be quite delicate and to be damaged in contact mode AFM [45]. To avoid this they applied a "jumping mode" technique, developed to study biological samples [53], in which the tip was withdrawn from the surface during scanning and only brought into contact for measurement [52]. With this method the authors were able to control the dynamics of the tip-induced rearrangement. They found that there were two time steps involved in the self-assembly, with initial rapid island formation and then slower growth due to diffusion of loosely bound molecules between the islands. Interaction of the AFM tip with the surface promoted molecular diffusion and assembly. It should be noted that since the surfaces were studied ex-situ, this diffusion and rearrangement was a $2 \mathrm{D}$ process, involving only the amine molecules that were left on the surface after withdrawal from solution. 
We cannot be certain of the mechanism by which changes in the morphology of the film occur during tapping mode AFM. However, we speculate that the tapping AFM tip brings about changes on the molecular level rather than causing delamination of the film and transportation of plate-like segments to new locations on the mica surface. We believe that augmentation of the height of the monolayer islands (Fig. $6 \mathrm{~d}$ ) and changes in the phase shift (Fig. $6 \mathrm{c}$ ), which is an indicator of the mechanical properties of the substrate, are evidence that the mechanism involves a more complex rearrangement of molecules on the molecular level rather than a simple transference of plate-like segments of film.

We hypothesise that initial adsorption of octadecylamine occurs very quickly upon injection of the octadecylamine solution in alkane and that the molecules initially adsorb in a non-ideal orientation, yet nevertheless are trapped in an energy well that is not the absolute energetic minimum for the system. We postulate that the tapping tip confers sufficient energy to the surface to facilitate the rearrangement of the octadecylamine molecules to give a lower energy molecular organisation where the film height is augmented and the molecular packing density within the SAM is increased.

It is interesting that changes in the morphology of the film are more readily observed at smaller scan sizes than at larger ones. Helt and Batteas used the contact radius $(\alpha)$ to line step ratio to determine the amount of contact area overlap that occurs in an AFM scan [54]. They showed that when the contact diameter $(2 \alpha)$ is greater than the line step that the scan will contain contact area overlap and that when the contact diameter is less than the line step, the scan will not contain contact area overlap. When the contact diameter is equivalent to the line step, all areas of the scanned surface will come into contact with the AFM tip whilst avoiding regions of overlap.

The Hertzian contact radius for the silicon nitride AFM tip-mica surface contact is found to be $1.60 \mathrm{~nm}$, i.e. contact diameter $=3.19 \mathrm{~nm}$. This is calculated for an AFM tip radius of curvature of $40 \mathrm{~nm}$ and a normal load of $6.8 \mathrm{nN}$ (cantilever deflection of $1 \mathrm{~V}$ ). The Poisson ratio and Young's modulus of silicon nitride are taken to be 0.24 and $220 \mathrm{GPa}$ respectively and the Poisson ratio and Young's modulus of mica are taken to be 0.25 and $60 \mathrm{GPa}$ respectively [54][55][56][57].

The line step is calculated by dividing the scan length by the image resolution. The number of lines in each AFM image is 256 , which, given the rastering motion of the tip, equates to 512 passes made across the surface during one scan. The line step is approximated to be $1.95 \mathrm{~nm}$ and $19.5 \mathrm{~nm}$ for scan lengths of $1 \mu \mathrm{m}$ and $10 \mu \mathrm{m}$ respectively. So, at a scan size of $1 \mu \mathrm{m}$, the line step is smaller than the contact diameter, suggesting overlap of successive line scans. However, at a scan size of $10 \mu \mathrm{m}$, the line step is greater than the contact diameter, suggesting that there is no overlap of successive line scans.

This means that at a scan size of $1 \mu \mathrm{m}$, a row of molecules along the fast-scan direction experience repeated stresses due to overlap of successive line scans which makes the molecules more likely to exhibit changes in morphology. At a larger scan size of $10 \mu \mathrm{m}$, the 
molecules do not experience repeated stresses, and there even exist molecules within the scanned region that do not come into contact with the tip; these molecules will not therefore exhibit tip-induced changes in morphology.

Determination of the strength of octadecylamine-mica bonding is complicated by fact that assumptions must be made about the nature of the mica surface and the chemistry of the amine headgroup. If it is assumed that the mica surface is anhydrous and water molecules do not adsorb onto the surface after cleavage in air, then the uppermost layer of mica will be composed of linked tetrahedra of $\mathrm{SiO}_{4}$ and $\mathrm{AlO}_{4}$ in the ratio 3:1 where the basal plane has 3 oxygen atoms from each tetrahedron; these are co-bonded to adjacent tetrahedral centres. As silicon and aluminium are below the basal plane of the surface, amine binding to these centres is unlikely for steric reasons. It is therefore probable that the amine interacts directly with oxygen on the basal plane of mica forming a $\mathrm{H}$-bond where amine is the proton donor and oxygen is the proton acceptor. Estimating the strength of $\mathrm{H}$-bonds is difficult because the bond energy is dependent on the geometry of the bond (respective bond lengths and bond angle) and the chemistry of the two interacting molecules [58]. Additionally, primary amines are capable of forming multiple hydrogen bonds and can act as both $\mathrm{H}$-bond donors and acceptors, so the amine headgroup may also participate in amine-amine bonding. Morukuma calculated the $\mathrm{H}$-bond interaction energy for several donors and acceptors [59][60]. The interaction energy of $\mathrm{H}_{2} \mathrm{~N}-\mathrm{H}----\mathrm{OH}_{2}$ is $-17.2 \mathrm{kJmol}^{-1}$, whilst that of $\mathrm{H}_{2} \mathrm{~N}-\mathrm{H}---$ $: \mathrm{NH}_{3}$ is $-17.6 \mathrm{kJmol}^{-1}$. n.b. The $\mathrm{H}$-bonding interaction energy for octadecylamine-mica will be different to that calculated for ammonia-water owing to the inductive effect of the alkyl substituent and because oxygen is locked within a crystal lattice.

If water is present at the mica surface, octadecylamine may be protonated to yield the octadecylammonium ion. This alkylammonium ion could $\mathrm{H}$-bond to water molecules at the mica surface and form a much stronger ionic $\mathrm{H}$-bonding interaction; $\mathrm{H}_{3} \mathrm{~N}^{+}-\mathrm{H}---: \mathrm{OH}_{2}$ has an interaction energy of $-156.1 \mathrm{kJmol}^{-1}$.

The lateral cohesive van der Waals interaction energy for a hexagonally packed monolayer of 18 -carbon alkyl chains is reported to be $-113.0 \mathrm{kJmol}^{-1}$ [61].

The lability of octadecylamine molecules observed during AFM suggests that amine-amine interactions are stronger than amine-mica interactions. Taking into account the approximate interaction energies it is found that on anhydrous mica, the total amine-amine interaction is stronger than the amine-mica interaction. This trend is reversed on hydrated mica where protonation of amine affords the formation of a stronger ammonium-mica bond. A mechanism for octadecylamine rearrangement and translation across the mica surface involving the breaking and formation of amine-mica $\mathrm{H}$-bonds via amine-amine $\mathrm{H}$-bonded intermediates seems possible, especially given the similar interaction energies of these two bonds.

Recently Benitez and his colleagues have applied ATR, FTIR and XPS to study the ex situ films formed by octadecylamine on mica [62][63]. They showed that the film present shortly 
after extraction from solution contains free amine, protonated amine, i.e. octadecylammonium cations, and also octadecylcarbamate anions formed by reaction of amine with $\mathrm{CO}_{2}$. Ripening of the film in air then leads to an increase in the proportion of ammonium ions to free amine and it is probably the consequent increase in repulsive forces between the headgroups of the adsorbed molecules that leads to a reduction in film packing and thus the observed increased tilt and reduced film thickness.

The current study is in broad agreement with the findings of Benitez and co-workers, both in terms of film morphology and film lability. The fact that similar rearrangement of the film in response to mechanical action was seen in Benitez' ex-situ work, where any molecular motion must occur along the film surface rather than via supernatant solution, suggests that 2D rearrangement due to activated diffusion across the surface is probably also predominant in the in the current in situ study.

The current study shows that the octadecylamine islands that are initially formed at room temperature are lost when the temperature is raised to about $35^{\circ} \mathrm{C}$, but reform when the temperature is lowered. This supports the supposition that they are relatively weakly bound. However, after extended immersion of 20 hours in octadecylamine solution, the islands structure is only lost above $60^{\circ} \mathrm{C}$. This suggests that the initial rapid, island-forming process is followed by a much slower consolidation, probably involving conversion of amine to ammonium ions and/or some octadecylcarbamate formation, as suggested by Benitez [53]. However, in this study, since the same sample was reheated after $20 \mathrm{~h}$, the effects of both immersion time and annealing (performing the initial heating-cooling cycle) may be significant. In future, it would be of interest to determine unambiguously whether the increased thermal stability observed during the second heating ramp is due to increased immersion time, the effect of annealing or indeed both of these factors.

It is not possible to determine from the results whether the islands desorb entirely upon heating or simply melt to form a disordered monolayer due to thermal breakdown of lateral alkyl chain interactions. Schwartz has discussed the possible transition between a solid-like vertically-oriented phase and a horizontally-oriented liquid phase dependent on surface concentration and temperature [31], so it is possible that the film adopts a disordered liquidlike structure at elevated temperature.

A few authors have studied the thermal response of self-assembled monolayers but most of these have been based on ex-situ approaches. Neves et al. prepared films of octadecylphosphonic acid monolayers on mica by quenching and studied these using AFM at a series of temperatures [64]. They found that the initially-formed island structure changed when temperature was raised above $100^{\circ} \mathrm{C}$, with the monolayer islands becoming disorganized and mobile molecules migrating across the surface to form precipitates. Sung and co-authors investigated the effect of heating and cooling on quenched octadecyltrichlorosilane monolayers on silica [65]. For films that were prepared at $10^{\circ} \mathrm{C}$ for only a short immersion time, they found that the island structure was lost on heating in chloroform to $60^{\circ} \mathrm{C}$ but reformed on re-cooling to $30^{\circ} \mathrm{C}$. However for films prepared over a 
longer initial immersion time the island structure persisted at $60^{\circ} \mathrm{C}$. The authors proposed that the difference represented the development of covalent linkages during a long preparation time, which resulted in the molecules becoming less mobile. Mellot and Schwartz studied the impact of temperature on the nature of the monolayer film formed by aqueous octadecyltrimethylammonium bromide on mica and found a critical temperature of $\sim 50^{\circ} \mathrm{C}$ below which the monolayer formed an island-type structure "within a matrix on disordered dilute phase" but above which a laterally homogeneous monolayer was formed [35]. The current study observed behaviour quite similar to Mellot and Schwartz, with the difference that there also appears to be an enhanced stability of the films over time, probably due to chemical changes [62].

One limitation of this study is that the chemistry of the mica surface is different to that of the metallic surfaces typically present where OFMs are employed in practice. Unfortunately, in situ AFM experiments on ferrous surfaces were unsuccessful as the increased surface roughness made interpretation of the results difficult. It is expected that the main difference will be in the nature of the amine-substrate interaction; on metal surfaces, the amine group may bind directly to metal centres where the nitrogen uses its lone pair of electrons to form a dative bond. However, fundamental studies using atomically smooth model mica surfaces, which allow the self-assembly of OFM molecules to be clearly characterised, are key to understanding the early stages of boundary film formation. In a separate study using saturated and mono-unsaturated carboxylic acid OFMs, in situ AFM permitted an understanding of how OFM chemistry affects film formation [22]. Additionally, ex situ AFM of rubbed quartz discs prepared in a sliding ball on disc tribometer where the ball counterface was of bearing steel, revealed that the film formed in stearic acid solution was similar to that observed on mica by in situ AFM. This demonstrates that in situ AFM studies employing model surfaces are relevant for understanding OFM behaviour in more conventional tribological contacts.

\section{$6 \quad$ CONCLUSIONS}

This paper describes the application of liquid cell AFM to study in situ the formation and properties of films formed on mica surfaces by octadecylamine from alkane solution.

Mica surfaces immersed in hexadecane or dodecane at room temperature show no identifiable surface films. However when octadecylamine solution is injected into the cell a boundary film forms almost immediately. This film takes the form of irregular islands of mean diameter approximately 1 to $3 \mu \mathrm{m}$ and thickness typically $1.5 \mathrm{~nm}$ when measured in contact mode. At the concentrations used, 0.001 to ca. $0.004 \mathrm{M}$, these islands covered typically $50 \%$ of the surface, a coverage that remained constant over time.

These islands are believed to correspond to patches of vertically-oriented but tilted octadecylamine or ammonium salt held together primarily by van der Waals forces between adjacent alkyl chains. These films are quite labile in that during scanning of the tip in both 
tapping and in contact mode changes to the shape of the islands takes place, including consolidation of the island density in the scanned region and depletion from around this area.

In situ experiments in which the temperature of the cell was varied over time showed that the initially-formed islands disappear at a temperature of $\mathrm{ca} .35^{\circ} \mathrm{C}$ but are reformed when the cell is re-cooled. Similar tests on samples that remained immersed in solution for extended periods showed more stable films, with islands being lost only above about $50-60^{\circ} \mathrm{C}$. This may reflect chemical changes to the adsorbed films, with slow conversion to octadecylammonium or carbamate ions [53].

The work shows that liquid cell AFM has great promise for studying the formation and properties of the boundary films formed by organic friction modifiers.

\section{ACKNOWLEDGEMENTS}

The authors would like to thank Castrol Ltd, UK for supporting the study described in this article.

\section{REFERENCES}

1. Koshima, H., Kamano, H., Hisaeda, Y., Liu, H., Ye, S.: Analyses of the adsorption structures of friction modifiers by means of quantitative structure-property relationship method and sum frequency generation spectroscopy. Tribology Online 5,165-172 (2010)

2. Wells, H.M., Southcombe, J.E.: The theory and practice of lubrication: the "Germ" process. J. Soc. Chem. Ind. 39, 51T-60T (1920)

3. Bowden, F.P., Leben, L.: The friction of lubricated metals. Phil. Trans. Roy. Soc. Lond. A239, 1-27, (1940)

4. Briscoe, B. J., Evans, D.C.B.: The shear properties of Langmuir-Blodgett layers. Proc. R. Soc. Lond. A 380, 389-407 (1982)

5. Meyer, E., Overney, R., Brodbeck, D., Howald, L., Lüthi, R., Frommer,J., Güntherodt, H.-J.: Friction and wear of Langmuir-Blodgett films observed by friction force microscopy. Phys. Rev. Lett. 69, 1777-1780 (1992)

6. Hutchinson, E., Rideal, E.K.: Adsorption and lubrication at crystal surfaces. Part I. On the boundary lubrication of sodium nitrate. Trans. Faraday Soc. 43, 435-438 (1947)

7. Hutchinson, E., Rideal, E.K.: On adsorption and lubrication at crystal surfaces. Part II. On the adsorption of paraffin chain compounds on sodium nitrate. Trans Faraday Soc. 43, 439-442 (1947) 
8. Greenhill, E.B.: The adsorption of long chain polar compounds from solution on metal surfaces. Trans Faraday Soc. 45, 625-635 (1949)

9. Jahanmir, S., Beltzer M.: An adsorption model for friction in boundary lubrication. ASLE Trans. 29, 423-430 (1986)

10. Allen, C.M., Drauglis, E.: Boundary layer lubrication: monolayer or multilayer. Wear 5, 363-384 (1969)

11. Spikes, H.A. Boundary lubrication and boundary films. Proc. 19th Leeds-Lyon Symposium on Tribology, Leeds, Sept. 1992, Thin Films in Tribology, 331-346. Publ. Elsevier 1993.

12. Cook, E.L., Hackermann, N.: Adsorption of polar organic compounds on steel. J Phys. Chem 55, 549-557 (1951)

13. Block, A., Simms, B.B., Desorption and exchange of adsorbed octadecylamine and stearic acid on steel and glass. J. Coll. \& Interf. Sci. 25, 514-518 (1967)

14 Ratoi, M., Anghel, V., Bovington, C., Spikes, H.A. Mechanisms of oiliness additives. Tribol. Intern. 33, 241-247 (2000)

15. Anghel, V. Bovington, C. and Spikes H.A.: Thick film formation by friction modifier additives. Lubr. Sci. 11, 313-335 (1999)

16. Piras, F.M., Rossi, A., Spencer, N.D.: Growth of tribological films: in situ characterization based on attenuated total reflection infrared spectroscopy. Langmuir $18,6606-6613$ (2002)

17. Beattie D.A., Winget, S.A., Bain, C.D.: Raman scattering from confined liquid films in the sub-nanometre regime. Tribol. Lett. 27, 159-167 (2007)

18. Beattie D.A., Haydcock, S., Bain, C.D.: A comparative study of confined organic monolayers by Raman scattering and sum-frequency spectroscopy. Vibr. Spect. 24, 109-123 (2000)

19. Topolovec-Miklozic, K., Spikes, H.A.: Application of AFM to the study of lubricant additive films. Trans. ASME J. of Trib. 127, 405-415, (2005)

20. Pidduck, A. J., Smith, G. C.: 'Scanning probe microscopy of automotive anti-wear films. Wear, 212, 254-264 (1997)

21. Topolovec Miklozic, K., Graham, J., Spikes, H.: "Chemical and physical analysis of reaction films formed by molybdenum dialkyldithiocarbamate friction modifier Additive using Raman and atomic force microscopy. Tribol. Lett., 11, 71-81 (2001) 
22. Campen, S., Greeen, J. H., Lamb, G. D., Spikes, H. A.: In situ study of model organic friction modifiers using liquid cell AFM; saturated and mono-unsaturated carboxylic acids. Submitted to Tribol. Lett.

23. Liu, S. Wang, Y.: Application of AFM in microbiology: a review. Scanning 32, 61-73 (2010)

24. Woodward, J.T., Schwartz, D.K.: In situ observation of self-assembled monolayer growth. J. Am. Chem. Soc. 118, 7861-7862 (1996)

25. Magonov, S. N., Whangbo, M.-H.: Surface Analysis with STM and AFM: experimental and theoretical aspects of image analysis. VCH Publishers: New York, 1996.

26. Li, B., Fujii, M., Fukada, K., Kato, T., Seimiya, T.: In situ AFM observation of heterogeneous growth of adsorbed film on cleaved mica surface. Thin Solid Films, 312, 20-23 (1998)

27. Xu, S., Cruchon-Dupeyrat, S.J.N., Garno, J.C., Liu, G.-Y., Jennings, G.K. ,Yong, T.-H., Laibinis, P.E.: In situ studies of thiol self-assembly on gold from solution using atomic force microscopy . J. Chem. Phys. 108, 5002-5012 (1998)

28. Doudevski, I., Hayes, W.A., Schwartz, D.K.: Submonolayer island nucleation and growth kinetics during self-assembled monolayer formation. Phys. Rev. Lett. 81, 4927-4930 (1998)

29. Resch, R., Grasserbauer, M., Friedbacher, G., Vallant, Th., Brunner, H., Mayer, U., Hoffmann, $H .:$ In situ and ex situ AFM investigation of the formation of octadecylsiloxane monolayers. Appl. Surf. Sci. 140, 168-175 (1999)

30. Leitner, T., Friedbacher, G., Vallant, T., Brunner, H., Mayer, U., Hoffmann, H.: Investigations of the growth of self-assembled octadecylsiloxane monolayers with atomic force microscopy. Mikrochim. Acta 133, 331-336 (2000)

31. Schwartz, D.K.: Mechanisms and kinetics of self-assembled monolayer formation. Annu. Rev. Phys. Chem. 52, 107-37 (2001)

32. Maoz R, Sagiv J. On the formation and structure of self-assembling monolayers. I. A comparative ATR-wettability study of Langmuir-Blodgett and adsorbed films on flat substrates and glass microbeads. J. Coll. Interf. Sci. 100, 465-496 (1984)

33. Nuzzo R.G, Allara D.L.: Adsorption of bifunctional organic disulfides on gold surfaces. J. Am. Chem. Soc. 105, 4481-4483 (1983)

34. Porter, M.D., Bright, T.B., Allara, D.L. Chidseyi, C.E.D.: Spontaneously organized molecular assemblies. 4. Structural characterization of $n$-alkyl thiol monolayers on gold by optical ellipsometry, infrared spectroscopy, and electrochemistry. J. Am. Chem. Soc., 109, 3559-3568 (1987) 
35. Mellott, J.M., Schwartz, D.K.: Supercritical self-assembled monolayer growth. J. Am. Chem. Soc. 126, 9369-9373, (2004).

36. Doudevski, I., Schwartz, D.K.: Dynamic scaling of the submonolayer island size distribution during self-assembled monolayer growth. Phys. Rev. B 60, 14-17 (1999)

37. Doudevski, I., Schwartz, D.K.: Self-assembled monolayers in the context of epitaxial film growth. Appl. Surf. Sci. 175-176, 17-26 (2001)

38. Doudevski, I., Schwartz, D.K.: Concentration dependence of self-assembled monolayer island nucleation and growth. J. Am. Chem. Soc. 123, 6867-6872 (2001)

39. Jiang, X., Zhang, X., Dai, S, Wang, D., Li, Y., Du, Z.: Reorganization of behenic acid monolayer on mica. Surf. Rev. Lett. 12, 59-66 (2005)

40. Zhang, L.-J., Zhang, Y., Zhang, R.-J., Feng, X.-S.: In situ AFM investigations on degradation of self-assembled monolayers on mica: Effect of humidity. Coll. and Surf. A: Physiochem. Eng. Aspects 293, 195-200 (2007)

41. Song, Y., Yao, Y., Chen, C., Cui, K., Wang, L.: Structural investigation of nhexadecanoic acid multilayers on mica surface: Atomic force microscopy study. Appl. Surf. Sci. 254, 3306-3312 (2008)

42. Benitez, J.J., Heredia-Guerrero, J.A., Heredia, A.: Self-assembly of carboxylic acids and hydroxyl derivatives on mica. A qualitative AFM study. J. Phys. Chem. C111, 9465-9470 (2007)

43. Wang, L., Jiang, J., Song, Y., Zhang, B., Wang, E.: Self-assembled monolayer growth of octanol on mica: Atomic force microscopy and Fourier-transform infrared spectroscopy studies. Langmuir 19, 4953-4957 (2003)

44. Wang, L., Song, Y., Zhang, B., Wang, E.: Adsorption behaviors of methanol, ethanol, n-butanol, n-hexanol and n-octanol on mica surface studied by atomic force microscopy. Thin Solid Films 458, 197-202, (2004).

45. Benitez, J.J., Kopta, S., Diez-Perez, I., Sanz, J., Ogletree, D.F., Salmeron, M.: Molecular packing changes in octadecylamine monolayers on mica induced by pressure and humidity. Langmuir 19, 762-765 (2003)

46. Benitez, J.J., Salmeron, M.: The influence of chain length and ripening time on the self-assembly of alkylamines on mica. J. Chem. Phys. 125, 044708 (2006)

47. Woodward, J.T., Doudevski, I., Sikes, H.D., Schwartz, D.K.: Kinetics of self-assembled monolayer growth explored via submonolayer coverage of incomplete films. J. Phys. Chem. B101, 7535-7541 (1997)

48. Cheng, H., Hu, Y.: Influence of chain ordering on frictional properties of self-assembled monolayers (SAMS) in nano-lubrication. Adv. Colloid Interface Sci. 171-172, 53-65 (2012) 
49. Ohler, B.: Practical advice on the determination of cantilever spring constants. Application note AN94, Veeco Instruments Inc., 2007.

50. Benitez, J.J., Kopta, S., Ogletree, D.F., Salmeron, M.: Preparation and characterization of self-assembled monolayers of octadecylamine on mica using hydrophobic solvents. Langmuir 18, 6096-6100 (2002)

51. Benitez, J.J., Ogletree, D.F., Salmeron. M.: Preparation and characterization of selfassembled multilayers of octadecylamine on mica from ethanol solutions. Langmuir 19, 3276-3281 (2003)

52. Benitez, J.J., Heredia-Guerrero, J.A., Salmeron, M.: Steering the self-assembly of octadecylamine monolayers on mica by controlled mechanical energy transfer from AFM tip. J. Phys. Chem. C114,12630-12634 (2010)

53. Moreno-Herrero, F., Colchero, J., Gomez-Rodruigez, J., Baro, A.M.: Atomic force microscopy contact, tapping, and jumping modes for imaging biological samples in liquids. Phys. Rev. E 69, 0231915 (2004)

54. Helt, J. M., Batteas, J. D.: Implication of the contact radius to line step (CRLS) ratio in AFM for nanotribology measurements. Langmuir 22, 6130-6141 (2006)

55. Zhang, G., Wei, Z., Ferrell, R. E.: Elastic modulus and hardness of muscovite and rectorite determined by nano-indentation. Appl. Clay Sci. 43, 271-281 (2009)

56. Bobko, C. P., Ortega, J. A., Ulm, F.-J.: Comment on "Elastic modulus and hardness of muscovite and rectorite determined by nano-indentation" by G. Zhang, Z. Wei and R. E. Ferrel. Appl. Clay Sci. 46, 425-428 (2009)

57. Mavko, G., Mukerji, T., Dvorkin, J.: 'The rock physics handbook', Cambridge University Press, New York, 1998

58. Steiner, T.: The hydrogen bond in the solid state. Angewandte Chemie International Edition, 41, 48-76 (2002)

59. Jeffrey, G.A.: An introduction to hydrogen bonding, Oxford University Press, Inc., New York (1997)

60. Morokuma, K.: Why do molecules interact? The origin of electron donor-acceptor complexes, hydrogen bonding and proton affinity. Acc. Chem. Res., 10, 294-300 (1977)

61. Shapiro, E.; Ohki, S.: The Interaction energy between hydrocarbon chains. J.Colloid Interface Sci. 47, 38-49 (1974)

62. Benitez, J.J.,San-Miguel, M.A., Dominguez-Meister, S., Heredia-Guerrero, J.A., Salmeron, M.: Structure and chemical state of octadecylamine self-assembled monolayers on mica. J. Phys. Chem. C115,19716-19723 (2011) 
63. Oviedo, J., San-Miguel, M.A., Heredia-Guerrero, J.A., Benitez, J.J.: Electrostatic induced molecular tilting of self-assembles monolayers of n-octadecylamine on mica. J. Phys. Chem. C116, 7099-7105 (2012)

64. Neves, B.R.A., Salmon. M.E., Russell, P.E., Troughton, E.B. Jr.: Thermal stability study of self-assembled monolayers on mica. Langmuir 16, 2409-2412 (2000)

65. Sung, M.M., Carraro, C., Yauw, O.W., Kim, Y., Maboudian, R.: Reversible liquid-liquid transitions in the early stages of monolayer self-assembly. J. Phys. Chem. B104, 14556-1559 (2000) 